\title{
OsRAM2 Function in Lipid Biosynthesis Is Required for Arbuscular Mycorrhizal Symbiosis in Rice
}

\author{
Ying-Na Liu, Cheng-Chen Liu, An-Qi Zhu, Ke-Xin Niu, Rui Guo, Li Tian, Ya-Nan Wu, Bo Sun, and \\ Bin Wang ${ }^{\dagger}$
}

School of Life Sciences, Nanjing University, Nanjing 210023, China

Accepted 31 May 2021.

\begin{abstract}
Arbuscular mycorrhiza (AM) is a mutualistic symbiosis formed between most land plants and Glomeromycotina fungi. During symbiosis, plants provide organic carbon to fungi in exchange for mineral nutrients. Previous legume studies showed that the required for arbuscular mycorrhization2 (RAM2) gene is necessary for transferring lipids from plants to AM fungi (AMF) and is also likely to play a "signaling" role at the root surface. To further explore RAM2 functions in other plant lineages, in this study, two rice (Oryza sativa) genes, OsRAM2 and $O S R A M 2 L$, were identified as orthologs of legume RAM2. Examining their expression patterns during symbiosis revealed that only $O S R A M 2$ was strongly upregulated upon AMF inoculation. CRISPR/Cas9 mutagenesis was then performed to obtain three Osram2 mutant lines (-1, -2, and -3). After inoculation by AMF Rhizophagus irregularis or Funneliformis mosseae, all of the mutant lines showed extremely low colonization rates and the rarely observed arbuscules were all defective, thus supporting a conserved "nutritional" role of $R A M 2$ between monocot and dicot lineages. As for the signaling role, although the hyphopodia numbers formed by both AMF on Osram2 mutants were indeed reduced, their morphology showed no abnormality, with fungal hyphae invading roots successfully. Promoter activities further indicated that $O s R A M 2$ was not expressed in epidermal cells below hyphopodia or outer cortical cells enclosing fungal hyphae but instead expressed exclusively in cortical cells containing arbuscules. Therefore, this suggested an indirect role of $R A M 2$ rather than a direct involvement in determining the symbiosis signals at the root surface.
\end{abstract}

Keywords: arbuscular mycorrhizal symbiosis, CRISPR/Cas9, OsRAM2, rice

${ }^{\dagger}$ Corresponding author: B. Wang; binwang@ @nju.edu.cn

Y.-N. Liu and C.-C. Liu contributed equally to this work.

Funding: This research was financed by National Natural Science Foundation of China (grant number 31870203) to B. Wang.

*The $\boldsymbol{e}$-Xtra logo stands for "electronic extra" and indicates there is supplementary material published online.

The author(s) declare no conflict of interest. the Creative Commons CCO "No Rights Reserved" license by waiving all of his or her rights to the work worldwide under copyright law, including all related and neighboring rights, to the extent allowed by law, 2022.
Arbuscular mycorrhiza (AM) is a mutualistic endosymbiosis formed between most land plants and Glomeromycotina fungi (Smith and Read 2008; Spatafora et al. 2016; Wang and Qiu 2006). Its developmental process involves several phases. Before physical contact, plant roots secrete a variety of compounds, including flavonoids, 2-hydroxy fatty acids, and strigolactones, to trigger nearby AM fungi (AMF) for hyphae elongation and branching (Akiyama et al. 2005; Bécard et al. 1992; Nagahashi and Douds 2011). In response, AMF produce lipochitooligosaccharides and short-chain chitooligosaccharides to activate plant symbiotic signaling pathways in epidermal cells, inducing nuclear $\mathrm{Ca}^{2+}$ spiking and early symbiotic gene expression (Genre et al. 2013; Kosuta et al. 2003; Maillet et al. 2011; Sun et al. 2015). After AMF contact the root surface, hyphal tips become swollen and flattened, forming adhesion structures called hyphopodia (Bonfante and Genre 2010). Below hyphopodia, tube-like structures designated as prepenetration apparatuses are assembled and guide fungi to invade the roots (Genre et al. $2005,2008,2012$ ). After reaching the inner cortex, fungi spread intercellularly along cortical cells and penetrate inside, developing highly branched, bush-like structures called arbuscules (Genre et al. 2008). Arbuscules are surrounded by a plantderived plasma membrane called the peri-arbuscular membrane (PAM). Through the interface of PAM and arbuscules, nutrient exchanges occur between symbiotic partners, where plants provide organic carbon to fungi and fungi supply mineral nutrients, especially phosphorus and nitrate, to plants (Smith and Smith 2011; Wang et al. 2017; Wang et al. 2020; Wipf et al. 2019).

Previous studies demonstrated that, during AM symbiosis, plants transfer sugars to fungi (An et al. 2019; Helber et al. 2011; Pfeffer et al. 1999; Shachar-Hill et al. 1995). However, within AMF, carbon is mainly transported and stored as lipids (Bago et al. 2002; Trépanier et al. 2005). Recent genomic studies revealed that AMF lack type I fatty acid synthase and, thus, are unable to synthesize palmitic acid (C16:0) de novo (Tang et al. 2016; Wewer et al. 2014). Therefore, these endosymbiotic fungi likely acquire palmitic acid from their plant partners.

Notably, lipid biosynthesis enzymes were found enriched in arbusculated cells (Gaude et al. 2012), and many genes involved in lipid metabolism evolved conservatively within plant species that engage in AM symbiosis (Bravo et al. 2016). One such gene, fat required for AM symbiosis (FatM), was recently characterized for its role in AM symbiosis. Expressed exclusively in arbusculated cells, FatM encodes an acyl carrier protein (acylACP) thioesterase, which preferentially releases palmitic acid in plastids. Free palmitic acid subsequently binds to coenzyme A (CoA) to form palmitoyl-CoA and is transported to the endoplasmic reticulum (ER) for lipid synthesis. In both legume species, Medicago truncatula and Lotus japonicus, mutated FatM led to significantly reduced AMF colonization and higher ratios 
of collapsed arbuscules, suggesting that palmitic acid is critical for successful symbiosis (Brands et al. 2018; Bravo et al. 2017; Jiang et al. 2017). In the ER, a sn-2 glycerol-3-phosphate acyl transferase (GPAT) enzyme, which is encoded by the required for arbuscular mycorrhization 2 (RAM2) gene, catalyzes palmitoyl-CoA and glycerol-3-phosphate (G3P) to form 2-monopalmitin (C16:0 2-monoacylglycerol [2-MAG]). Mutated $R A M 2$ in M. truncatula and L. japonicus results in more severe phenotypes than the fatm mutant, where AMF colonization rates dramatically decrease and the rarely observed arbuscules are all defective (Bravo et al. 2017; Jiang et al. 2017; Keymer et al. 2017; Luginbuehl et al. 2017; Wang et al. 2012). Furthermore, two half-size ATP-binding cassette transporters of subfamily $\mathrm{G}$ (ABCG), which are encoded by the stunted arbuscule (STR) and STR2 genes, also affect arbuscule development in Medicago (Zhang et al. 2010). ABCG transporters have been found to export lipids (Bird et al. 2007; Hwang et al. 2016; Pighin et al. 2004), thus, it is hypothesized that the STR/STR2 heterodimer located on the PAM is involved in lipid transfer from plant cells to peri-arbuscular apoplastic spaces for AMF assimilation (Bravo et al. 2017; Jiang et al. 2017). Collectively, these findings indicate that lipids serve as a major carbon source in plants that support fungal growth, development, and reproduction, during which RAM2 plays an essential "nutritional" role in transforming palmitoyl-CoA to 2-monopalmitin for late transportation (Bravo et al. 2017; Jiang et al. 2017; Keymer et al. 2017; Luginbuehl et al. 2017).

Additionally, the M. truncatula RAM2 (MtRAM2) gene was previously hypothesized to play a "signaling" role at the root surface (Murray et al. 2013; Wang et al. 2012). The close homologs of RAM2 in Arabidopsis thaliana exhibited specific functions of providing precursors for extracellular lipids such as cutin and suberin (Yang et al. 2012). After inoculation by AMF Rhizophagus irregularis, significantly reduced hyphopodia numbers were observed on the Medicago ram 2 mutant. Such a phenotype was hypothesized to be caused by lack of a symbiosis "signal" at the root surface, which was supported by observing that the exogenous addition of cutin monomers (e.g., C16 $\omega$-hydroxy fatty acids, 16-OHFA) could rescue the hyphopodia formation phenotype on the Medicago ram 2 roots (Wang et al. 2012). However, it was later reported that, when a different AMF (Glomus versiforme) was used, the hyphopodia numbers were not significantly reduced on the Medicago ram 2 mutants, and the reduced colonization levels were explained by a reduction in ability to spread within the root cortex instead of having difficulty in gaining entry to the roots (Bravo et al. 2017). Therefore, it remains uncertain whether the hyphopodia numbers do, indeed, reduce in ram2 mutants and, if they do, whether this phenotype is controlled by host plants, AMF, or even both. To clarify this issue, we suggest investigating ram 2 mutants in other plant species.

In this study, we aimed to identify $R A M 2$ orthologs and close homologs in rice, to analyze their expression patterns during AM symbiosis, and, more importantly, to obtain Osram2 mutants for AM phenotype examinations, including the hyphopodia numbers. The close homologs of RAM2 in A. thaliana (AtGPAT4, AtGPAT6, and AtGPAT8) were all expressed in epidermis cells ( $\mathrm{Li}$ et al. 2007; $\mathrm{Li}$ et al. 2012; Li-Beisson et al. 2009). Also, an M. truncatula gene, ENOD11, which encodes a putative cell-wall-repetitive, Pro-rich-secreted protein, was expressed specifically in the hyphopodia region at the early phase of symbiosis (Chabaud et al. 2002). Studying the $M t R A M 2$ promoter with a $\beta$-glucuronidase $(G U S)$ reporter gene, however, revealed strong activities in arbusculated cells only (Gobbato et al. 2013; Luginbuehl et al. 2017). It remains uncertain whether $R A M 2$ exhibits transient expression in epidermal cells at the early phase of AM symbiosis, as MtENOD11 exhibited. Thus, in this study, we also studied the promoter activities of the OsRAM2 gene during the early and late phases of AM symbiosis.

\section{RESULTS}

Os03g52570 and Os10g27330 are orthologous to MtRAM2.

Using the MtRAM2 protein sequence, BLASTp searches against the rice proteome identified 16 GPAT homologs (Supplementary Table S1), among which 2 top hits were encoded by Os03g52570 and Os $\log 27330$, and exhibited 86 and $81 \%$ overall similarity to MtRAM2, respectively, while others showed 50 to $72 \%$ similarity. To identify the real orthologs of MtRAM2 in rice, a phylogenetic tree including 82 GPAT sequences from seven angiosperm species (see Materials and Methods) was reconstructed (Fig. 1; Supplementary Table S1). The tree comprises six highly supported monophyletic subclades with bootstrap values ranging from 65 to 100 . To be consistent with a previous work (Waschburger et al. 2018), these subclades were named subclades a, b, c, d, e1, and e2. Noticeably, both rice genes (OsO3g52570 and Os10g27330) were included in subclade c containing MtRAM2, indicating that these genes share a recent common ancestor with MtRAM2 and are real orthologs (hereafter, we refer to $O s 03 g 52570$ as $O s R A M 2$ and $O s 10 g 27330$ as $O s R A M 2 L$ ). It seems that OsRAM2 and OsRAM2L originated from a duplication event that occurred in the common ancestor of the Poaceae family. In another surveyed Poaceae species, Brachypodium distachyon, an additional duplication event resulted in a third gene in this subclade; however, rice had lost this third gene. In the surveyed Brassicaceae species A. thaliana and Brassica rapa, no representative gene was found for this subclade, indicating losses of the RAM2 orthologs in these nonmycorrhizal species. Also, the surveyed species Phaseolus vulgaris possessed a single gene, while Solanum lycopersicum evolved three genes in this subclade. Subclades $a$ and $b$ formed a sister relationship and these two subclades together showed a sister relationship with subclade c (Fig. 1). Therefore, OsO2g02340 in subclade a and Os01g63580 and Os05g37600 in subclade b represent three close paralogs of MtRAM2 in rice.

\section{OsRAM2 was strongly induced during AM symbiosis.}

The transcriptome data from rice roots at 4,5 , and 6 weeks postinoculation (wpi) by $R$. irregularis provided preliminary clues on the expression patterns of OsRAM2, OsRAM2L, and their close paralogs during AM symbiosis (Fig. 2A). Showing little expression in the mock-inoculated roots, OsRAM2 was strongly induced upon inoculation by AMF $R$. irregularis. The transcript abundance of $O S R A M 2$ at 5 and 6 wpi was 10- and 16-times higher than at 4 wpi, respectively, indicating enhanced functioning of OsRAM2 as mycorrhizal symbiosis develops into the late phase (Fig. 2A). OsRAM2L, however, showed a rather low expression level in rice roots and no induction pattern after AMF inoculation at any of the three examined time points. Os $02 g 02340$ from subclade a showed a noninduction pattern similar to that of $O s R A M 2 L$. As for the genes in subclade b, Os05g37600 had no detectable transcripts in rice roots, while 0 s01g63580 exhibited increased expression at 4 wpi by AMF but not at 5 or 6 wpi (Fig. 2A).

To further verify the expression patterns of these genes, quantitative reverse-transcription (qRT)-PCR assays were performed (Fig. 2B). At $3 \mathrm{wpi}$, the relative expression levels of OsRAM2 increased approximately 18-fold in AMF-inoculated roots compared with the control $(P=0.06)$. At $6 \mathrm{wpi}, O s R A M 2$ expression increased approximately 168 -fold in mycorrhizal roots $(P<0.02)$. In contrast, upon inoculation by AMF, the relative expression levels of OsRAM2L, OsO2g02340, and Os01g63580 did not show statistically significant changes at either 3 or 6 wpi. Together, these results showed us that, within subclades a, b, and c, OsRAM2 represents the only 
GPAT member that is strongly induced upon AMF $R$. irregularis inoculation in rice roots.

\section{Acquiring Osram2 mutants via CRISPR/Cas9 mutagenesis.}

To obtain null Osram 2 mutants in rice, two independent single-guide RNAs (sgRNAs) were designed, with one matching nucleotides 679 to 698 in exon 1 and the other matching nucleotides 1,574 to 1,593 in exon 2 (Fig. 3A). The sgRNAs were independently incorporated into Clustered Regularly Interspaced Short Palindromic Repeats (CRISPR)/Cas9 vector pRGEB31 and introduced into rice calli through Agrobacterium-mediated transformation (see Materials and Methods). Regenerated rice seedlings were screened for edited Osram 2 alleles. In total, six mutated alleles were detected in the $\mathrm{T}_{0}$ generation (Supplementary Fig. S1A). Three of these mutated alleles (Osram2-1, -2, and -3 ) were selected for obtaining their homozygotes in subsequent generations, as well as to eliminate the pRGEB31 vector (Fig. 3B; Supplementary Fig. S1). By introducing a nucleotide insertion, the mutant alleles of Osram2-1 and -3 had altered reading frames after the insertions. Consequently, their encoded

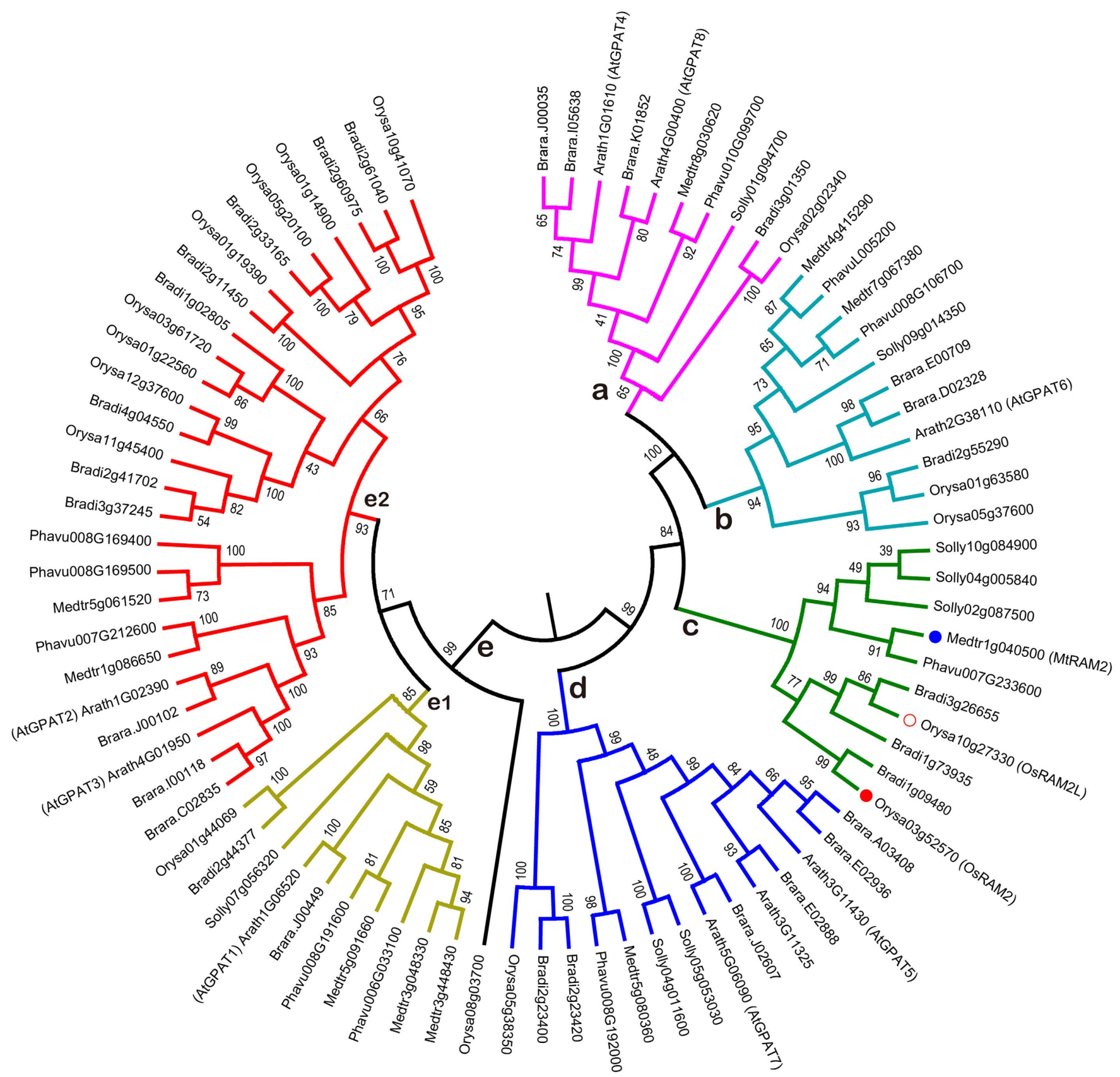

Fig. 1. A phylogenetic tree consisting of 82 clade III glycerol-3-phosphate acyl transferase (GPAT) sequences from seven representative angiosperms. The tree was built using the maximum-likelihood method, implemented by Mega v7.0 with default parameters settings. In total, 500 bootstrap replicates were performed to obtain support values (\%) on each internal branch. The seven plant species include Oryza sativa (Orysa), Brachypodium distachyon (Bradi), Arabidopsis thaliana (Arath), Brassica rapa (Brara), Medicago truncatula (Medtr), Phaseolus vulgaris (Phavu), and Solanum lycopersicum (Solly). Six monophyletic subclades were revealed, including subclade a (pink), subclade b (cyan), subclade c (green), subclade d (blue), subclade e1 (golden yellow), and subclade e2 (red). MtRAM2 (blue dot) was found in subclade c along with two rice orthologous genes, OsRAM2 (red dot) and OsRAM2L (red circle). The eight Arabidopsis clade III sequences (AtGPAT1 to AtGPAT8) were distributed in five subclades (except subclade c) and also labeled. 
A

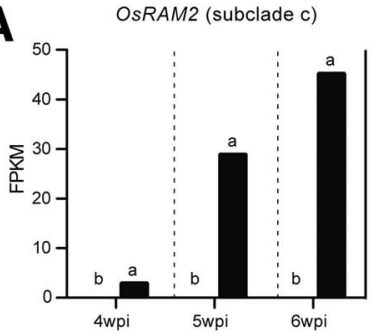

B

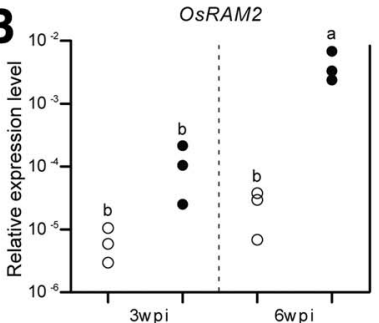

OSRAM2L (subclade c)
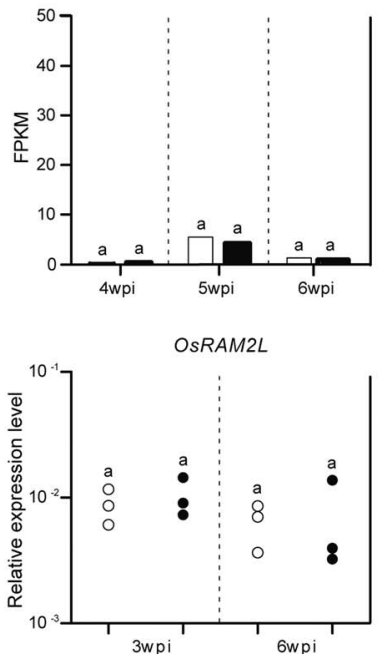

Os02g02340 (subclade a)
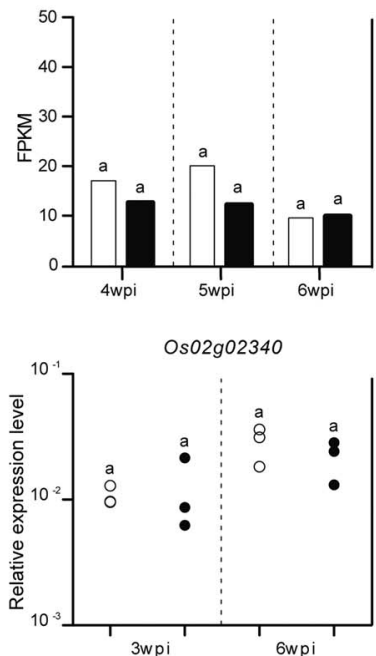

Os01g63580 (subclade b)
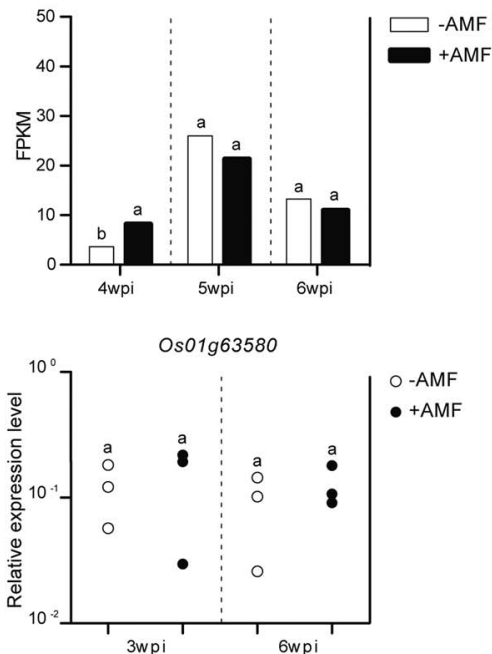

Fig. 2. Expression patterns of $O S R A M 2$, OSRAM2L, and their close paralogs during arbuscular mycorrhiza (AM) symbiosis. A, Transcript abundances of OsRAM2, OsRAM2L, Os02g02340, and OsO1g63580 were measured by RNA-Seq. Abundance values are expressed as fragments per kilobase of exon per million (FPKM) reads mapped. Rice wild-type roots were either mock inoculated (negative AM fungi [-AMF]) or colonized by Rhizophagus irregularis (+AMF) at 4, 5, and 6 weeks postinoculation (wpi). Different letters indicate significant differences between the groups $(P<0.05)$. B, Relative expression levels of these genes were measured by quantitative reverse-transcription PCR at 3 and 6 wpi by $R$. irregularis. Gene expression values were normalized to the rice housekeeping gene ubiquitin $1(O s U B I 1)$. Statistical analysis was performed using the Student's $t$ test with a $P<0.05$ significance threshold.

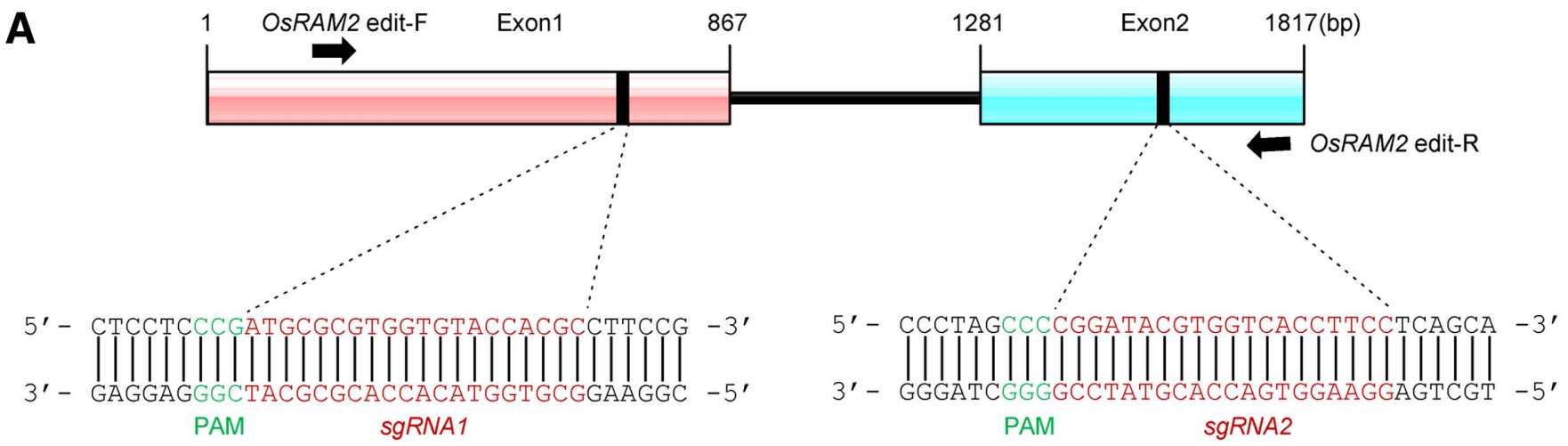

B

\begin{tabular}{llcc}
\hline sgRNA & $\begin{array}{l}\text { Plant } \\
\text { line }\end{array}$ & Sequence & $\begin{array}{c}\text { Insertion } \\
\text { /Deletion }\end{array}$ \\
\hline sgRNA1 & WT & CGGAAGGCGTGGTACACCACGCGCATCGGGAGGAG & \\
& Osram2-1 & CGGAAGGCGTGGTACACCACGCGACATCGGGAGGAG & $+1 \mathrm{nt}$ \\
sgRNA2 & WT & TGCTGAGGAAGGTGACCACGTATCCGGGGCTAGGG & $-12 \mathrm{nt}$ \\
& Osram2-2 & TGCTGAGGAAGGTGA-----------GGCTAGGG & $+1 \mathrm{nt}$ \\
& Osram2-3 & TGCTGAGGAAGGTGACCACGTATTCCGGGGCTAGGG & \\
\hline
\end{tabular}

Fig. 3. CRISPR/Cas9-mediated OsRAM2 gene mutagenesis in rice. A, Schematic gene structure of $O s R A M 2$, which contained two exons (pale red and cyan rectangles, respectively). The two black vertical rectangles represent the targeted sites of designed single-guide RNAs (sgRNAs) within the coding sequence. Target sequences are shown in red letters and protospacer adjacent motif (PAM) sites are shown in green letters. Positions and orientations of the OsRAM2 edit-F and OsRAM2 edit-R primers, which were used to detect the editing alleles of OsRAM2, are indicated by black arrows. B, Nucleotide sequence alignments of the sgRNA target regions showed altered alleles in three $\mathrm{T}_{1}$ homozygous mutant lines. Acquired mutated alleles are shown below the wild-type (WT) sequences. Black dashes indicate deleted nucleotides and underlined letters indicate inserted nucleotides; - and + indicate deletions and insertions of several nucleotides (nt), respectively. 
proteins shared no homology with the wild-type enzyme (467 amino acids [aa]) after amino acid sites 227 and 388, respectively (Supplementary Fig. S2). Because the conserved acyltransferase domain is located at the $\mathrm{C}$ terminus, it can be expected that neither the Osram2-1 nor Osram2-3 alleles encodes a functional enzyme. Moreover, the mutant allele Osram2-2 had a proper reading frame but showed a deletion of 12 nucleotides from sites 1,573 to 1,584 . Accordingly, 4 aa (PGYV at sites 387 to 390) were missing in the enzyme encoded by Osram2-2 (Supplementary Fig. S2). The Pro on site 387 and Tyr on site 389 are conserved among different subclades of plant GPATs (Supplementary Fig. S3), and missing these sites could potentially disrupt the OsRAM2 function, which awaits further examination.

To see whether the knockout OsRAM2 gene would affect the growth and development of rice plants, the three obtained Osram 2 mutant lines were grown together with wild-type rice. As far as we can tell, no abnormal developmental phenotypes were observed for these mutant lines (Supplementary Fig. S4). This is consistent with the extremely low expression levels of OsRAM2 gene in rice roots, stems, and leaves under normal growth condition (data not shown).

\section{All Osram2 mutants displayed severely impaired AM phenotypes after inoculation by $R$. irregularis or Funneliformis mosseae.}

We then examined the mycorrhizal phenotypes of Osram2 mutants. After inoculation by $R$. irregularis for 6 weeks, the lateral roots of wild-type rice were heavily infected, with approximately $87 \%$ root length colonized by intraradical fungal hyphae and approximately 59\% root length forming arbusculated cells for nutrient exchange (Fig. 4A). In contrast, all three Osram2 mutants showed severely impaired AM phenotypes. Only 7 to $11 \%$ of root length of these Osram 2 mutants was colonized by intraradical hyphae and less than $1 \%$ of roots formed arbuscules (Fig. 4A). Without fully occupying the spaces of inner cortical
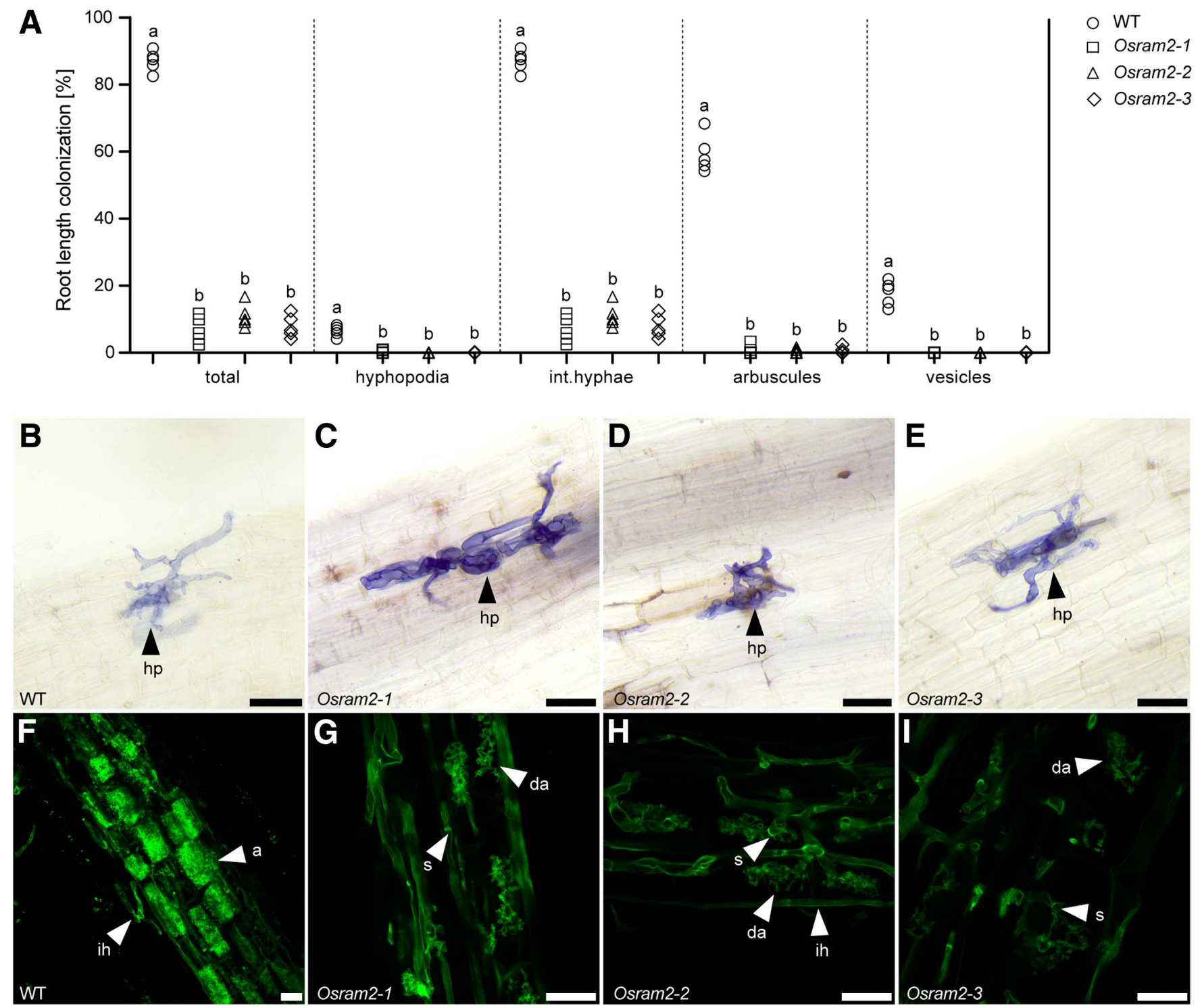

Fig. 4. OSRAM2 is required for arbuscular mycorrhiza fungi (AMF) colonization by Rhizophagus irregularis. A, Root length colonization (\%) of wildtype (WT) rice and Osram 2-1, -2, and -3 mutants at 6 weeks postinoculation (wpi) was determined by the gridline intersect method. Different letters indicate statistical differences: analysis of variance, posthoc Tukey, $n=20 ; F(\text { total })_{3,16}=638.53, F(\text { hyphopodia })_{3,16}=73.85, F($ intraradical hyphae $[$ int . hyphae $)_{3,16}=638.53, F(\text { arbuscules })_{3,16}=489.09$, and $F(\text { vesicles })_{3,16}=115.65 ; P<0.001$. B to $\mathbf{E}$, Images of the ink-vinegar staining of the hyphopodia in Osram 2 and WT rice roots; $\mathrm{hp}=$ hyphopodia. Scale bars $=30 \mu \mathrm{m}$. F to I, Images of the green fluorescent signals after WGA-Alexa Fluor 488 staining of the fungal cell walls. Laser-scanning confocal images showing arbuscule development in WT and Osram2 rice roots. Mycorrhizal structures were indicated: $\mathrm{a}=$ arbuscules, $\mathrm{ih}=$ intraradical hyphae, $\mathrm{da}=$ defective arbuscules, and $\mathrm{s}=$ septa. Scale bars $=20 \mu \mathrm{m}$. 
cells as in wild-type rice roots (Fig. 4F), the arbuscules of the three Osram 2 mutants all looked small and distorted, with septa often seen in collapsed fungal hyphae (Fig. 4G to I). Therefore, OsRAM2 is required for developing normal arbuscules. Consistently, although approximately $18 \%$ of wild-type rice roots showed the lipid-storage vesicles, no vesicles could be found in the mutants' roots (Fig. 4A), supporting the idea that the nutrient supply from plants to fungi had been largely, if not completely, blocked. To also see whether OsRAM2 could potentially play a signaling role at the root surface, the numbers of fungal entry structures (hyphopodia) were counted. Although they could be seen on approximately $7 \%$ of wildtype rice roots, rather few $(<1 \%)$ were detected on the mutant roots $(P<0.01)$ (Fig. 4A). However, compared with those on wild-type rice roots, the hyphopodia formed on mutants showed no morphological difference (at least in our view), and the fungal hyphae below hyphopodia were capable of invading root cells successfully (Fig. 4C to E).
To explore whether a different AMF species may induce altered AM phenotypes (especially the hyphopodia numbers) on Osram 2 mutants, we further inoculated the rice ram2 mutants with another AMF species, Funneliformis mosseae. Likely due to the weak inoculum strength of this species (see Materials and Methods), overall lower colonization rates by $F$. mosseae than by $R$. irregularis were obtained for the wild-type rice plants (Fig. 5). Despite this, similar defective AM phenotypes were observed on Osram 2 mutants (Fig. 5A). Again, the hyphopodia numbers formed on the mutants were significantly fewer than those observed on the wild-type rice (1 versus 10\%) (Fig. 5A) but, still, the hyphopodia morphology appeared normal on the mutants (Fig. 5C to E). As with $R$. irregularis, $F$. mosseae also rarely formed arbuscules in mutants' roots $(<1 \%)$, and they were all defective (Fig. 5G to I). Therefore, for both AMF species used, similar impaired AM phenotypes were observed on all three Osram 2 mutants.
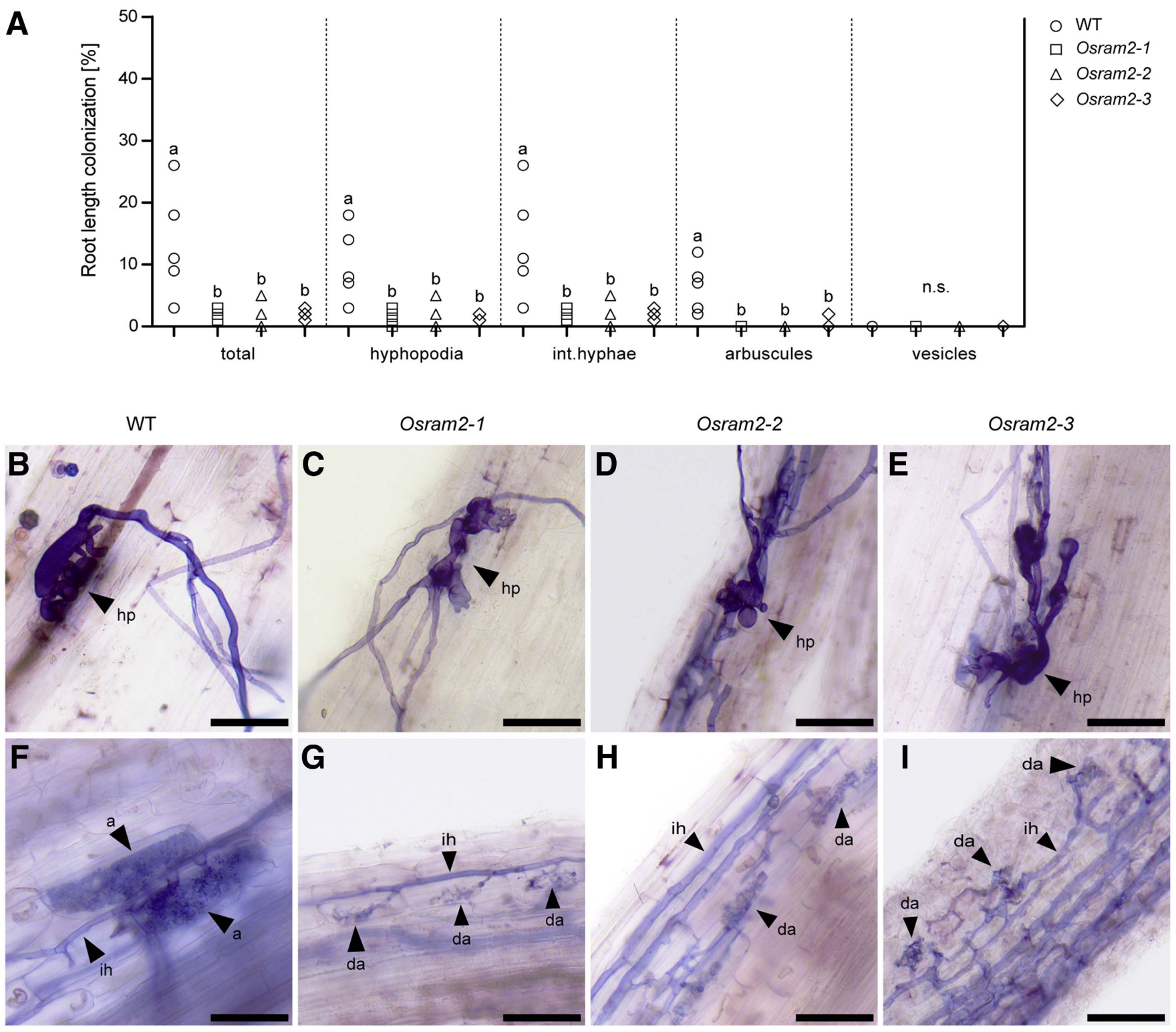

Fig. 5. OsRAM2 is required for arbuscular mycorrhiza fungi (AMF) colonization by Funneliformis mosseae. A, Root colonization levels of wild-type (WT) rice and Osram 2 mutants at 6 weeks postinoculation (wpi). Different letters indicate statistical differences: analysis of variance, posthoc Tukey, $n=20 ; F(\text { total })_{3,16}=6.30, F(\text { hyphopodia })_{3,16}=5.11, F\left(\right.$ intraradical hyphae $[\text { int. hyphae })_{3,16}=6.30$, and $F(\text { arbuscules })_{3,16}=4.23 ; P<0.05 ;$ n.s. $=$ no significance. B to I, Images of the ink-vinegar staining of the fungal hyphae showing the normal hyphopodia morphology and defective arbuscules morphology in Osram2 (C to E and G to I) mutants compared with the WT rice roots (B and F). Mycorrhizal structures were indicated: hp = hyphopodia, $\mathrm{a}=$ arbuscules, $\mathrm{ih}=$ intraradical hyphae, and $\mathrm{da}=$ defective arbuscules. Scale bars $=50 \mu \mathrm{m}$. 
For several AM marker genes, their relative expression levels were measured by qRT-PCR. At 3 or 6 wpi by $R$. irregularis, the examined AM marker genes (OsAM1, OsAM3, and OsPT11) all showed significantly reduced expression levels in the three Osram 2 mutants (Fig. 6), indicating that symbiosis in these Osram 2 mutants was not established successfully. This is consistent with the observed defective mycorrhizal phenotypes (Fig. 4). For $O s R A M 2$ itself, the relative transcript abundance was also significantly reduced in the mutants (Fig. 6). To see whether such changes could potentially influence the expression of its close homologs, the transcriptional levels of OsRAM2L, Os02g02340, and Os01g63580 were examined in Osram2-1 and -3 mutants. Results revealed that the knockout OsRAM2 gene did not alter the transcript abundances of the three homologs in rice roots (Supplementary Fig. S5).

OsRAM2 was not expressed in epidermis cells below hyphopodia but exclusively in arbusculated cells during the early and late phases of AM symbiosis.

To determine the temporal and spatial expression patterns of OsRAM2, a 3.1-kb promoter region of OSRAM2 was fused to a
GUS reporter gene. Stable transgenic rice lines were obtained to establish symbiosis. At 7 to 10 days postinoculation (dpi), expression of GUS proteins was not observed in any parts of the transgenic rice roots, including the epidermis layer (Fig. 7A and D). At $11 \mathrm{dpi}$, however, blue stains were observed in a few lateral roots and microscopic examination revealed that these blue stains were all located in root cortical cells (Fig. 7B and E). Counterstaining with ink-vinegar and WGA-Alexa Fluor 488 further revealed that the blue stains did not appear in epidermal cells below hyphopodia (Fig. 7F) or outer cortical cells enclosing intraradical hyphae (Fig. 7H and I; Supplementary Fig. S6C) but appeared predominantly in cortical cells containing mature arbuscules (Fig. $7 \mathrm{H}$ and I; Supplementary Fig. S6A to D). Noticeably, some cortical cells containing young or small arbuscules showed no blue stains (Fig. $7 \mathrm{G}$ to I; Supplementary Fig. S6B), suggesting that OsRAM2 is not expressed until a late developmental stage of arbuscules. At 21 and $28 \mathrm{dpi}$, a significant portion of rice lateral roots had blue GUS stains (Fig. 7C; Supplementary Fig. S6E and F). Cross and longitudinal sections of these lateral roots confirmed the presence of blue stains in many cortical cells,
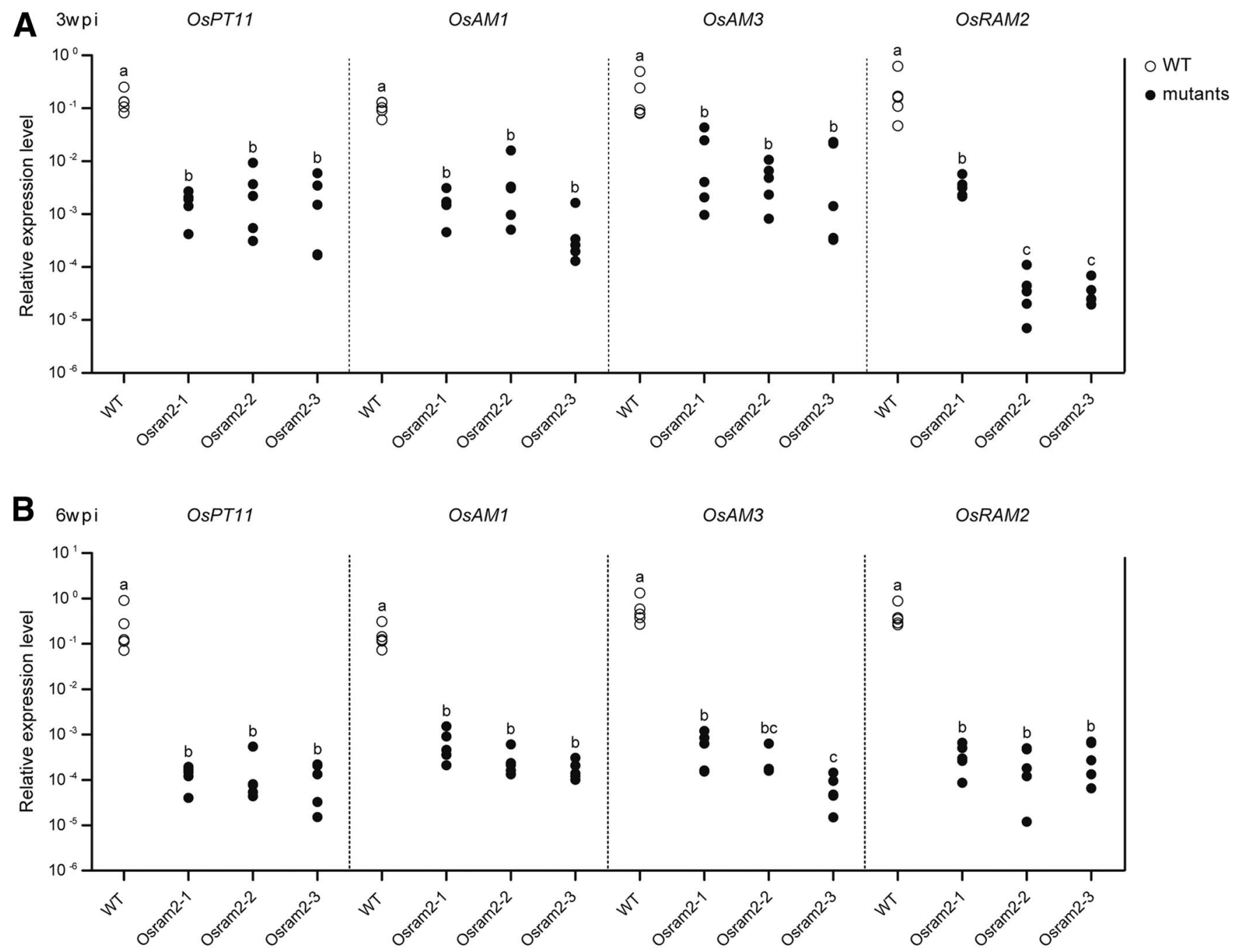

Fig. 6. Arbuscular mycorrhiza (AM) marker gene expression in Osram 2 mutants. Transcript accumulation of OsPT11, OsAM1, OsAM3, and OsRAM2 were measured by quantitative reverse-transcription PCR in wild-type (WT) and Osram 2 mutants at A, 3 weeks postinoculation (wpi) and B, 6 wpi by Rhizophagus irregularis. Housekeeping gene OsUBII was used for normalization. Different letters indicate levels of statistical significance (analysis of variance, posthoc Tukey); $n=20, P<0.001, F(O s P T 11)_{3,16}=22.33 ; P<0.001, F(O s A M 1)_{3,16}=57.39 ; P<0.01, F(O s A M 3)_{3,16}=5.44 ;$ and $P<0.05$, $F(\text { OsRAM2 })_{3,16}=4.62(\mathrm{~A})$ and $n=20, P<0.05, F(\text { OsPT11 })_{3,16}=3.66 ; P<0.001, F(O s A M 1)_{3,16}=14.08 ; P \leq 0.001, F(O s A M 3)_{3,16}=9.66 ;$ and $\left.P<0.001, F(\text { OsRAM2 })_{3,16}=14.23\right)(\mathrm{B})$. 
some of which were even close to the epidermis and exodermis layers (Fig. 7J and K).

\section{DISCUSSION}

AM symbiosis is an extremely ancient type of mutualism, which has been documented by the fossil records of AM-like associations in some primitive vascular plants, including Aglaophyton major and Horneophyton lignieri ( $>407$ million year ago) (Remy et al. 1994; Strullu-Derrien et al. 2014; Taylor et al. 1995). Despite its ancient origin and a wide occurrence in extant land plants, our current understanding of the developmental process and underlying mechanisms of AM symbiosis has been largely achieved by studying a few model angiosperm organisms, especially legumes such as $M$. truncatula and $L$. japonicus. Thus far, $>60$ plant genes regulating AM symbiosis at various developmental phases have been reported (MacLean et al. 2017). For many of these genes, including $R A M 2$, their roles in AM symbiosis have only been characterized in legumes, leaving their evolution and functions largely unexplored in other plant lineages. In this study, we aimed to identify $R A M 2$ orthologs in rice and further investigate their expression patterns and potential roles in AM symbiosis.

MtRAM2 encodes a GPAT enzyme that is required for AM symbiosis (Wang et al. 2012). This type of enzyme has a specific function in lipid synthesis by transferring acyl group from acyl-CoA onto G3P. In land plants, three separate clades of GPAT genes have been reported, in which clades I and II both exhibit a conservative evolutionary pattern, while clade III have diverged into multiple sublineages (Waschburger et al. 2018). In the Arabidopsis genome, for example, aside from $A t G$ PAT9 belonging to clade I and At 1932200 in clade II, nine GPAT genes (AtGPAT1 to AtGPAT8 and At3g11325) were assigned to clade III (Waschburger et al. 2018). Studies on these Arabidopsis GPATs revealed that the GPATs of clades I and II both exhibit a $s n-1$ acyl transfer regiospecificity onto G3P and are mainly responsible for synthesizing cell membranes and storage lipids, whereas the GPATs in clade III all exhibit $s n-2$ acyl transfer regiospecificity and are mainly involved in synthesizing extracellular lipids such as cutin and suberin (Beisson et al. 2012; Yang et al. 2012).

To clarify the evolutionary relationships of MtRAM2 with its close GPAT homologs, we reconstructed a robust GPAT clade III gene phylogeny covering 82 sequences from seven representative angiosperm species (Fig. 1; Supplementary Table S1). Six monophyletic subclades (a, b, c, d, e1, and e2) were identified (Fig. 1), revealing that at least six GPAT sublineages had evolved in the common ancestor of surveyed angiosperms. Noticeably, MtRAM2 was found in subclade $\mathrm{c}$ along with two rice genes, three Brachypodium distachyon genes, one $P$. vulgaris gene, and three
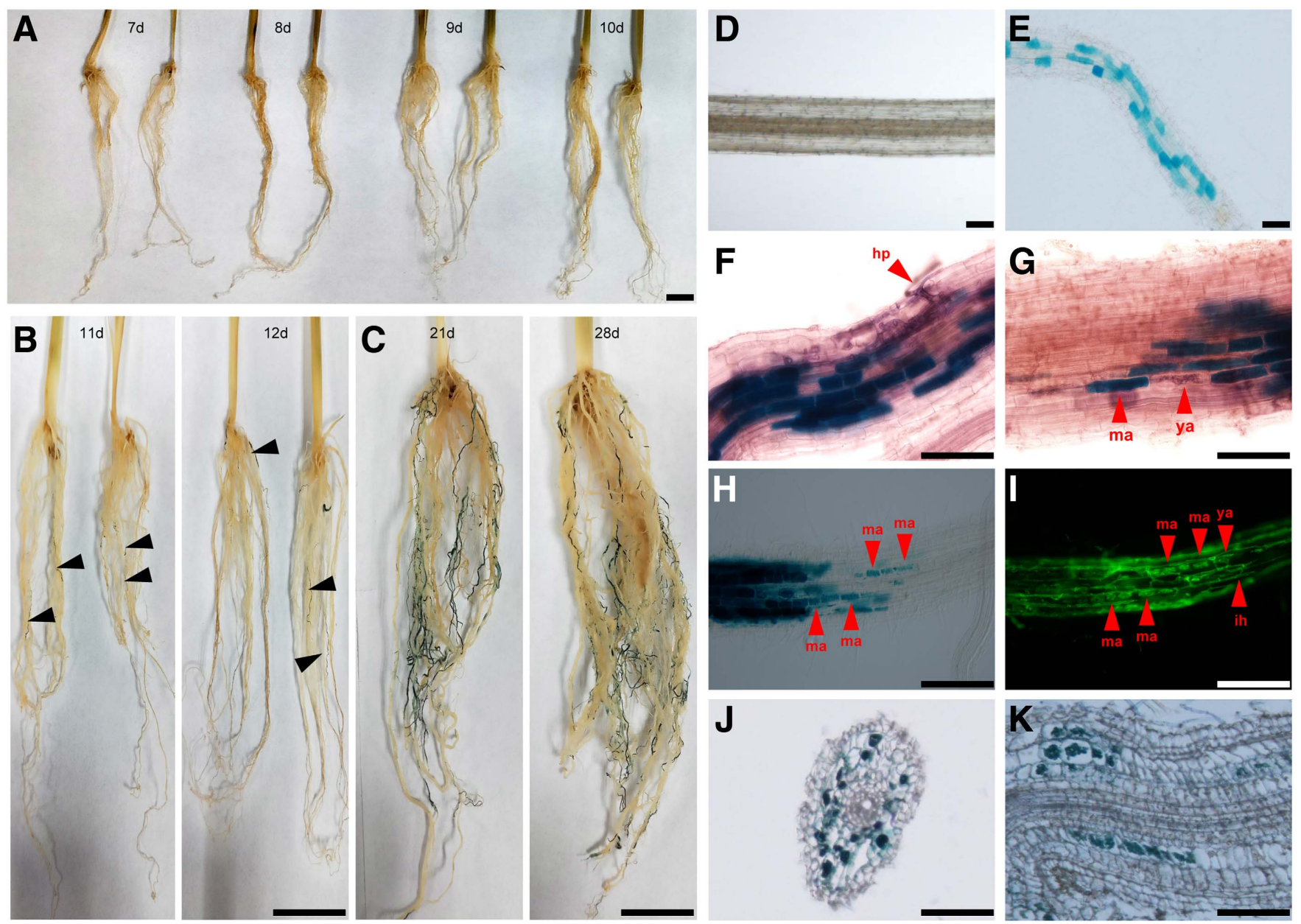

Fig. 7. Promoter activity of OsRAM2 in Rhizophagus irregularis-colonized rice roots. A, $\beta$-Glucuronidase (GUS) activity was examined from 7 to 10 days postinoculation (dpi) by R. irregularis. B, OsRAM2 promoter activity was detected at 11 and 12 dpi by blue GUS staining. Black arrowheads indicate roots containing GUS activity. C, More rice roots displayed blue GUS stains at 21 and 28 dpi. D, OsRAM2pro:GUS roots lacked GUS staining, while E, blue stains appeared in root cortical cells at 11 dpi. F to I, Counterstaining with ink-vinegar or WGA-Alexa Fluor 488 revealed that blue stains appeared in cortical cells containing developed arbuscules at 11 dpi. Red arrowheads indicate fungal structures: hp = hyphopodia, ih = intraradical hyphae, ya = young arbuscules, and ma = mature arbuscules. $\mathbf{J}$ and $\mathbf{K}$, Images of cross and longitudinal sections of rice lateral roots at 28 dpi. Scale bars $=1 \mathrm{~cm}(\mathrm{~A}$ to $\mathrm{C})$ or $100 \mu \mathrm{m}$ (D to $\mathrm{K})$. 
S. lycopersicum genes (Fig. 1). No representative sequences from the two surveyed nonmycorrhizal species (Arabidopsis thaliana and Brassica rapa) were found in this subclade, indicating that a possible function of this sublineage is involved in AM symbiosis. Such a result is consistent with the findings of a previous phylogenomic study (Bravo et al. 2016). According to the resolved gene relationships within this subclade, OsRAM2 and OsRAM2L represent the real orthologs of MtRAM2 (Fig. 1).

Subclade $\mathrm{c}$ lies in an intermediate phylogenetic position between subclades $\mathrm{d}$ and $\mathrm{a}+\mathrm{b}$ (Fig. 1). Previously, in A. thali$a n a$, it was demonstrated that AtGPAT4 and AtGPAT8 (subclade a) were essential for $\mathrm{C} 16$ and $\mathrm{C} 18$ cutin monomer formation in the stems and leaves ( $\mathrm{Li}$ et al. 2007), and AtGPAT6 (subclade b) was required for incorporating $\mathrm{C} 16$ monomers into flower cutin (Li-Beisson et al. 2009). In contrast, AtGPAT5 (subclade d) was involved in accumulating $\mathrm{C} 22$ and $\mathrm{C} 24$ suberin monomers in the roots and seed coats (Beisson et al. 2007), and AtGPAT7 (subclade d) also took part in suberin synthesis in response to wounding (Yang et al. 2012). Like the AtGPAT4, AtGPAT6, and AtGPAT8 enzymes, Medicago RAM2 strongly prefers C16 and C18 $\omega$-oxidized acyl-CoA (Wang et al. 2012; Yang et al. 2012). Moreover, unlike AtGPAT5 (subclade d) and AtGPAT1 (subclade e1), which possess only acyltransferase activity to generate $s n$-2 lysophosphatidic acids (LPA), AtGPAT4, AtGPAT6, and AtGPAT8 (subclades a and b) all have a functional phosphatase domain that remove the phosphate group from LPA to generate 2-MAGs (Yang et al. 2010, 2012). MtRAM2 in subclade $\mathrm{c}$ also possesses the phosphatase domain and mainly synthesizes C16:0 2-MAGs in arbusculated cells during AM symbiosis (Bravo et al. 2017; Jiang et al. 2017; Luginbuehl et al. 2017). When driven by the MtRAM2 promoter, the AtGPAT6 gene can fully complement the ram 2 mutant phenotype during AM symbiosis, whereas AtGPAT5 exhibits only weak complementation (Wang et al. 2012). Therefore, in terms of enzyme function, the GPATs of subclades a, b, and $c$ are analogous to each other.

We then examined the expression patterns of OsRAM2 and OsRAM2L in subclade c, Os02g02340 in subclade a, and Os01g63580 and $0 s 05 g 37600$ in subclade b during AM symbiosis. Four genes, except $0 s 05 g 37600$, were expressed in rice roots. Among these genes, only OsRAM2 was strongly induced upon $\mathrm{AMF} R$. irregularis inoculation under our experimental conditions and the transcript abundance level of $O S R A M 2 L$ gene was only approximately $2 \%$ of the $O s R A M 2$ gene at 6 wpi by $R$. irregularis (Fig. 2). This induction pattern of $O s R A M 2$ is also consistent with the transcriptome data of two previous studies (Fiorilli et al. 2015; Roth et al.2018).

We then focused on the OsRAM2 gene and tried to obtain its knockout mutants using the CRISPR/Cas9 mutagenesis technique. Three homozygous mutant lines (Osram2-1, -2, and -3) were obtained (Fig. 3) and their AM phenotypes were further examined. After inoculation by $R$. irregularis, all Osram 2 mutants showed dramatically reduced fungal colonization (Fig. 4). Strikingly, the arbuscules were observed in very few $(<1 \%)$ of the examined rice roots and they were all defective (Fig. $4 \mathrm{G}$ to I). Consistent with such low colonization rates, the expression levels of several AM marker genes (OsAM1, OsAM3, and OsPT11) were significantly reduced in the mutant lines compared with the wild type (Fig. 6). Among them, OsAMI and $O s A M 3$ represent early-expressed AM marker genes and OsPT11 is a late-expressed gene during symbiosis (Gutjahr et al. 2008). Expression of OsAM1 was detected in cortical cells containing small arbuscules and cells entrapping intercellularly growing hyphae, while OsAM3 and OsPT11 transcripts were activated in arbusculated cells only (Gutjahr et al. 2008). The low expression levels of the three marker genes in the Osram 2 mutants indicate that the knockout of OsRAM2 would block the development of AM symbiosis in rice roots. All of these results are consistent with several recent legume studies, which had proposed a nutritional role of $R A M 2$ in the arbusculated cells (Bravo et al. 2017; Jiang et al. 2017; Keymer et al. 2017; Luginbuehl et al. 2017).

Previously, Wang et al. (2012) observed significantly fewer hyphopodia in the Medicago ram 2 mutant when inoculated by AMF $R$. irregularis. Because close homologs of MtRAM2 in Arabidopsis (the AtGPAT4, AtGPAT6, and AtGPAT8 genes) were all involved in synthesizing cutin monomers at the plant surface, it was hypothesized that MtRAM2 likely plays a signaling role at the root surface and, therefore, affects hyphopodia formation (Wang et al. 2012). However, it was later reported that, when a different AMF species (G. versiforme) was used, the hyphopodia numbers were not significantly reduced in the Medicago ram2 mutants (Bravo et al. 2017). To further clarify this issue, in this work, we used not only $R$. irregularis but also another AMF species, F. mosseae, to inoculate rice Osram 2 mutant plants. Pure spores of $R$. irregularis were extracted from transgenic hairy carrot roots, while the $F$. mosseae inoculum was a mixture of granular inoculum propagated with moso bamboo. For both AMF, a significant reduction of the hyphopodia numbers was observed between wild-type rice and Osram2 mutants (Figs. 4A and 5A), thus supporting the results of earlier work (Wang et al. 2012). Therefore, why were the results of the other work (Bravo et al. 2017) inconsistent with these observations? A very strong AMF inoculum might be used, as indicated by up to 10 hyphopodia numbers per centimeter of colonized roots in the wild-type plants, or the observation was made at a rather early stage (Bravo et al. 2017).

OsRAM2 promoter activities showed no sign of expression in epidermal cells below hyphopodia or outer cortical cells enclosing intraradical hyphae (Fig. 7F, H, and I; Supplementary Fig. S6C) but were strongly expressed in cortical cells containing developed arbuscules (Fig. 7G; Supplementary Fig. S6A, B, and D). Such expression patterns would favor the nutritional rather than signaling hypothesis. The reduction of hyphopodia numbers on mutants could also be explained by the nutritional hypothesis, because a defective nutritional supply in arbusculated cells would limit the spread of both intra- and extraradical fungal hyphae on Osram 2 mutants and, consequently, fewer hyphopodia would be formed. Such an explanation was certainly not in mind when the signaling hypothesis was first proposed. For the pathogenic oomycete Phytophthora palmivora, the evidence supporting a signaling role of RAM2 gene was also reported (Wang et al. 2012). In an accompanying work, Dai and colleagues $(\mathrm{H}$. L. Dai, X. W. Zhang, B. Y. Zhao, N. Yu, and E. T. Wang, unpublished) further showed that, in rice, OsRAM2 function in lipid synthesis is required for successful colonization by rice blast fungi in roots.

Even without observing the expression of OSRAM2 in the epidermis, we cannot preclude a possibility that $R A M 2$ may indirectly affect fatty acid compositions at the root surface. Because some arbusculated cells are very close to the root epidermis and exodermis layers (Fig. 7J and K), accumulated C16:0 2-MAGs in arbusculated cells may be passively diffused or actively transferred from cortical cells toward the root surface, which consequently affects hyphopodia formation. A rice gene encoding a lipid transfer protein (LTP) was previously revealed to be induced at the penetration stage of AMF and specifically expressed in the epidermal root regions where the hyphopodia were formed (Blilou et al. 2000). Moreover, a new study focusing on a liverwort (Marchantica paleacea) just revealed that a RAM2 gene homolog was mainly expressed at the outmost cell layer of thalli upon AMF inoculation (Rich et al. 2021), indicating a shift of expressional position of RAM2 gene to cortical cells in angiosperms species, including rice and Medicago. An 
interesting observation was also made in the fossil records of two primitive vascular plants, A. major and $H$. lignieri, which both showed abundant AM fungal structures in their aerial stems (Remy et al. 1994; Strullu-Derrien et al. 2014; Taylor et al. 1995), suggesting that, in the early history of land plant evolution, AMF was likely attracted by cutin monomers on the stem surface. It was also revealed that vanillic acid (4-hydroxy-3methoxy benzoic acid, $\left.\mathrm{C}_{8} \mathrm{H}_{8} \mathrm{O}_{4}\right)$ found in the cell wall extracts of Daucus carota roots (an AM host) can efficiently stimulate AMF hyphal growth and branching, while ferulic acid (4-hydroxy-3-methoxy cinnamylic acid, $\mathrm{C}_{10} \mathrm{H}_{10} \mathrm{O}_{4}$ ), which is found mainly in Beta vulgaris roots (a non-AM host), inhibited AMF growth (Douds et al. 1996). AMF probably relies on recognizing certain cell wall components present in the host root surface to form hyphopodia; however, the exact component and which genes (the exact function of OSLTP remains elusive) directly affect its composition at the root surface remain unknown. Therefore, the signaling hypothesis is still intriguing but requires further in-depth investigation.

In summary, in this study, we identified the true orthologs of $M T R A M 2$ in rice and exploited reverse genetic tools to demonstrate that $O s R A M 2$ is indispensable for rice mycorrhizal symbiosis. Our findings on the temporal and spatial expression patterns of $O s R A M 2$ provided further understanding of the early-raised signaling hypothesis of RAM2.

\section{MATERIALS AND METHODS}

\section{Phylogenetic reconstruction \\ using $R A M 2$ homologous sequences.}

A previous work reported that land plants possess three clades of GPAT genes (Waschburger et al. 2018). MtRAM2 as well as its close homologs in Arabidopsis belong to the expanded landplant-specific clade III (Wang et al. 2012; Yang et al. 2012). To identify RAM2 orthologs in rice and clarify their relationships to other close GPAT homologs, we used the MtRAM2 protein sequence to perform BLASTp searches against the proteomes of seven representative angiosperm species, including Oryza sativa, Brachypodium distachyon, A. thaliana, Brassica rapa, Medicago truncatula, Phaseolus vulgaris, and S. lycopersicum in the Phytozome database v12.1. All identified GPAT homologous sequences were aligned by ClustalW and used to reconstruct a phylogenetic tree by the maximum-likelihood method, implemented by MEGA v7.0 (Supplementary Table S1) (Kumar et al. 2016). The robustness of the internal branches was tested by performing a total of 500 bootstrap replicates. The obtained tree was examined to elucidate the relationships of different subclades and the subclade containing MtRAM2 was identified.

\section{Plant growth and the establishment of AM symbiosis.}

Rice ( $O$. sativa subsp. japonica 'Nipponbare') seed were sterilized with $2.5 \%$ sodium hypochlorite and $0.1 \%$ Tween 20 for $15 \mathrm{~min}$ and $70 \%$ alcohol for $2 \mathrm{~min}$, rinsed three times with distilled water, and germinated on modified Murashige-Skoog (MS) medium (MS basal salts at $2.165 \mathrm{~g} /$ liter, sucrose at $20 \mathrm{~g} / \mathrm{liter}, \mathrm{Fe}_{2}$-EDTA at $5 \mathrm{mg} / \mathrm{liter}$, vitamins at $10 \mathrm{mg} / \mathrm{liter}$, and Phytagel at $3 \mathrm{~g} /$ liter; $\mathrm{pH} 6.1$ to 6.3). For AM colonization, seedlings were transplanted in pods (diameter $=12 \mathrm{~cm}$ ) containing an autoclaved sand/perlite (3:1) mixture with three seedlings per pot. AM fungus $R$. irregularis spores were freshly extracted from transgenic hairy carrot root cultures and approximately 200 spores were added to the rhizosphere of each seedling. $F$. mosseae (formerly G. mosseae; BGC HK01), obtained from the Institute of Plant Nutrition and Resources, Beijing Academy of Agriculture and Forestry Sciences (Beijing, China) and propagated with moso bamboo (Phyllostachys pubescens) as a host plant, were used as another mycorrhizal fungus. The granular inoculum was a mixture of mycorrhizal roots, hyphae, and spores. Inoculum (6 g) containing approximately 100 spores was added uniformly as a layer in each pot at a depth of $20 \mathrm{~mm}$ from the soil surface upon planting. Plants were placed in a growth room under a photoperiod of $16 \mathrm{~h}$ of light and $8 \mathrm{~h}$ of darkness at 28 and $22^{\circ} \mathrm{C}$, respectively, and were fertilized twice a week with half-strength Hoagland solution containing $20 \mu \mathrm{M}$ phosphates. Plant roots were collected at 3, 4, 5, and 6 wpi, where half of the samples were used for staining and mycorrhizal phenotype examination and the other half were frozen in liquid nitrogen and kept at $-80^{\circ} \mathrm{C}$ for RNA extraction.

\section{RNA extraction, sequencing, and qRT-PCR.}

The total RNA of rice roots was extracted by the Trizol method (Invitrogen, Carlsbad, CA, U.S.A.). RNA purity and integrity were examined by RNA electrophoresis in $2.5 \%$ (wt/ vol) agarose gel. Transcriptome sequencing was conducted on a BGISEQ-500 sequencing platform (BGI, Shenzhen, China) and the data were analyzed by the Hua-Da Gene Technology Co. (Shenzhen, China).

RNA ( $1 \mu \mathrm{g})$ was treated with DNase I prior to cDNA synthesis using a Revert-Aid First-Strand cDNA Synthesis Kit (Thermo Scientific, Waltham, MA, U.S.A.). qRT-PCR was performed by measuring the intensity of SYBR Green fluorescent dye conjugated to double-stranded DNA molecules using a C1000 Thermal Cycler Real-Time PCR detection system (Bio-Rad, Hercules, CA, U.S.A.). Gene expression values were normalized to the rice housekeeping gene, ubiquitin 1 (OsUBII) (Chen et al. 2008), and analyzed by the $2^{-\Delta \Delta \mathrm{CT}}$ method (Livak and Schmittgen 2001). Statistical differences were tested via Student's $t$ test or analysis of variance followed by Tukey's multiple comparison test $(P<$ $0.05)$. All qRT-PCR primers used in this study are provided in Supplementary Table S2.

\section{Rice transformation.}

Callus from the transformed rice cultivar Nipponbare was generated by placing surface-sterilized mature seed on induction medium (N6 basal salts at $3.98 \mathrm{~g} /$ liter, sucrose at $30 \mathrm{~g} /$ liter, 2,4dichlorophenoxyacetic acid [2,4-D] at $2.5 \mathrm{mg} / \mathrm{liter}$, vitamins at $10 \mathrm{mg} /$ liter, N-Z-Amine at $0.6 \mathrm{~g} / \mathrm{liter}$, L-Proline at $0.3 \mathrm{~g} / \mathrm{liter}$, and Phytagel at $3 \mathrm{~g} / \mathrm{liter}$; $\mathrm{pH} 6.2$ to 6.4 ). Plates were sealed with parafilm and cultured in the dark at $26^{\circ} \mathrm{C}$ for 5 weeks. Before transformation, calli were placed on preculture medium (N6 basal salts at $1.99 \mathrm{~g} / \mathrm{liter}$, sucrose at $20 \mathrm{~g} / \mathrm{liter}, \mathrm{Fe}_{2}$-EDTA at $5 \mathrm{mg} / \mathrm{liter}, 2,4-\mathrm{D}$ at $3 \mathrm{mg} / \mathrm{liter}$, vitamins at $10 \mathrm{mg} / \mathrm{liter}$, $\mathrm{N}-\mathrm{Z}$-Amine at $0.6 \mathrm{~g} /$ liter, agarose at $7 \mathrm{~g} /$ liter, glucose at $10 \mathrm{~g} /$ liter, and acetosyringone at $19.6 \mathrm{mg} / \mathrm{liter}$; $\mathrm{pH} 5.9$ to 6.1) for 3 days. Meanwhile, Agrobacterium strain EHA105 containing transformed vectors was cultured at $28^{\circ} \mathrm{C}$ for 2 days on yeast extract broth medium. Bacteria were scraped from the plate and added to approximately $50 \mathrm{ml}$ of suspension liquid medium (N6 basal salts at $1.99 \mathrm{~g} / \mathrm{liter}$, sucrose at $20 \mathrm{~g} / \mathrm{liter}$, 2,4-D at $2 \mathrm{mg} /$ liter, vitamins at $10 \mathrm{mg} /$ liter, $\mathrm{N}$-Z-Amine at $0.8 \mathrm{~g} /$ liter, glucose at $10 \mathrm{~g} / \mathrm{liter}$, and acetosyringone at $19.6 \mathrm{mg} / \mathrm{liter}$; $\mathrm{pH} 5.7$ to 5.9 ) and the optical density at 600 $\mathrm{nm}$ was adjusted to 1.0. Precultured calli were transferred to a conical flask containing the suspension liquid medium and shaken gently at $100 \mathrm{rpm}$ for $30 \mathrm{~min}$. Next, the calli were transferred to coculture medium (N6 basal salts at $1.99 \mathrm{~g} / \mathrm{liter}$, sucrose at $20 \mathrm{~g} / \mathrm{liter}, \mathrm{Fe}_{2}$-EDTA at $5 \mathrm{mg} / \mathrm{liter}, 2,4-\mathrm{D}$ at $3 \mathrm{mg} / \mathrm{liter}$, vitamins at $10 \mathrm{mg} / \mathrm{liter}, \mathrm{N}-\mathrm{Z}$-Amine at $0.8 \mathrm{~g} / \mathrm{liter}$, agarose at $7 \mathrm{~g} /$ liter, glucose at $10 \mathrm{~g} /$ liter, and acetosyringone at $19.6 \mathrm{mg} / \mathrm{liter}$; $\mathrm{pH} 5.9$ to 6.1 ) for 3 days at $19^{\circ} \mathrm{C}$ in the dark.

After coculturing, calli were washed with sterile water five times, soaked in a solution containing carbenicillin at $0.5 \mathrm{~g} / \mathrm{liter}$, and shaken for $30 \mathrm{~min}$ at $200 \mathrm{rpm}$. Then, calli were placed on selection medium (N6 basal salts at $3.98 \mathrm{~g} /$ liter, sucrose at 
$30 \mathrm{~g} /$ liter, 2,4-D at $2.5 \mathrm{mg} / \mathrm{liter}$, vitamins at $10 \mathrm{mg} / \mathrm{liter}, \mathrm{N}-\mathrm{Z}$ Amine at $0.6 \mathrm{~g} / \mathrm{liter}$, agarose at $7 \mathrm{~g} /$ liter, carbenicillin at $0.5 \mathrm{~g} /$ liter, and hygromycin or other appropriate antibiotics at $50 \mathrm{mg} /$ liter; $\mathrm{pH} 6.3$ to 6.5 ) and cultured at $26^{\circ} \mathrm{C}$ in the dark. Every 2 to 3 weeks, vigorous calli were transferred to fresh selection medium for growth. After 5 to 6 weeks, resistant calli that were pale yellow in color were transferred to conical flasks containing regeneration medium (MS basal salts at $4.33 \mathrm{~g} / \mathrm{liter}$, sucrose at $30 \mathrm{~g} / \mathrm{liter}$, vitamins at $10 \mathrm{mg} / \mathrm{liter}$ 6-benzylaminopurine at $2 \mathrm{mg} / \mathrm{liter}$, kinetin at $2 \mathrm{mg} /$ liter, naphthalene acetic acid at $0.2 \mathrm{mg} / \mathrm{liter}$, indole 3 -acetic acid at $0.2 \mathrm{mg} / \mathrm{liter}, \mathrm{N}-\mathrm{Z}$ Amine at $1 \mathrm{~g} /$ /iter, and Phytagel at $3 \mathrm{~g} /$ liter; $\mathrm{pH} 6.3$ to 6.5) and cultured under a photoperiod of $16 \mathrm{~h}$ of light and $8 \mathrm{~h}$ of darkness at 28 and $22^{\circ} \mathrm{C}$, respectively. After a month, regenerated seedlings were transferred to rooting medium (MS basal salts at $2.165 \mathrm{~g} /$ liter, sucrose at $20 \mathrm{~g} / \mathrm{liter}, \mathrm{Fe}_{2}$-EDTA at $5 \mathrm{mg} / \mathrm{liter}$, vitamins at $10 \mathrm{mg} /$ liter, and Phytagel at $3 \mathrm{~g} /$ liter; $\mathrm{pH} 6.1$ to 6.3) for root growth. After 2 weeks, rice seedlings were transplanted in soil for growth. To identify positively transformed seedlings, genomic DNA was extracted from the leaves using a modified cetyltrimethylammonium bromide method (Murray and Thompson 1980), which was subjected to PCR using specific primers of transformed vectors (Supplementary Table S2).

\section{CRISPR vector construction and obtaining Osram2 mutant lines.}

To generate Osram mutants, the CRISPR-Cas9 technique was employed. sgRNA targeting OsRAM2 was designed using the CRISPR-PLANT and CRISPRdirect online tools (Naito et al. 2015; Xie et al. 2014). The two best-scored sgRNAs (sgRNA1 and sgRNA2) showing the least off-target possibilities were selected and their spacer sequences upstream of the protospacer adjacent motif sites targeted exons 1 and 2 of OsRAM2. For each sgRNA, a pair of complementary primers with sticky ends was synthesized, annealed, and ligated with a linear CRISPR vector, pRGEB31, which was predigested by the restriction enzyme BsaI (Supplementary Table S2). After transforming rice by Agrobacterium containing the pRGEB31-sgRNA1 and pRGEB31-sgRNA2 vectors, the editing alleles of OsRAM2 were examined through PCR and sequencing with a pair of primers (OsRAM2 edit-F/R) which cover both editing regions (Fig. 3A; Supplementary Table S2). In subsequent generations, plants carrying desired homozygous mutations without the pRGEB31 construct, which can be detected by $p R$ REB31-Cas9-F/R, were selected for reproduction (Supplementary Table S2). Finally, the $\mathrm{T}_{2}$ or $\mathrm{T}_{3}$ generations of the three mutant lines (Osram2-1, Osram2-2, and Osram2-3) were used for AM colonization assays and gene expression studies.

\section{Fungal structure staining and quantification.}

For wheat germ agglutinin (WGA) staining (Schaffer and Peterson 1993), fresh rice roots were fixed in 50\% ethanol for $>4 \mathrm{~h}$ and cleared in $20 \% \mathrm{KOH}$ (wt/vol) for 2 to 3 days at room temperature. Next, the roots were rinsed five times with phosphate-buffered saline (PBS) solution ( $\mathrm{pH} \mathrm{7.4)}$ and acidified in $0.1 \mathrm{M} \mathrm{HCl}$ for $20 \mathrm{~min}$. After incubating overnight in PBS solution containing WGA-Alexa Fluor 488 (Invitrogen, Eugene, OR, U.S.A.) at $1 \mu \mathrm{g} / \mathrm{ml}$ in the dark and washing with PBS, the WGA-stained roots were examined under a confocal Olympus FV10-ASM microscope (Olympus, Tokyo, Japan). For inkvinegar staining (Vierheilig et al. 1998), fresh rice roots were cleared with $20 \% \mathrm{KOH}$ for 40 to $120 \mathrm{~min}$ at $65^{\circ} \mathrm{C}$, acidified by $5 \%$ acetic acid for $5 \mathrm{~min}$ at room temperature, incubated in inkvinegar solution for $30 \mathrm{~min}$ at $65^{\circ} \mathrm{C}$, and decolored in tap water for $14 \mathrm{~h}$. The stained roots were examined under a Nikon E100 microscope (Nikon, Tokyo, Japan). To quantify the fungal colonization rate, a modified gridline intersect method was used to observe fungal structures (McGonigle et al. 1990), including hyphopodia, intraradical hyphae, arbuscules, and vesicles scored.

\section{Constructing the OsRAM2pro:GUS vector and GUS staining.}

A 3.1-kb fragment upstream of the OsRAM2 start codon was amplified by a pair of primers carrying the Sal1 and BamH1 restriction sites (Supplementary Table S2), then cloned into an intermediate vector, pEASY-Blunt Zero, by TA cloning (Transgene, Beijing, China). The fragment was further digested from the intermediate vector using the Sal1 and BamH1 enzymes and ligated with a predigested linear binary vector, pBI101.1. Subsequently, the constructed $\mathrm{pBI} 101.1$ vector containing the OsRAM2pro:GUS reporter unit was introduced to the Agrobacterium strain EHA105 and used to transform rice callus. Positively transformed seedlings were identified by PCR using the primers PBI101.1-F and OsRAM2pro-R (Supplementary Table S2), which were selected for seed propagation. In the $\mathrm{T}_{1}$ generation, positively transformed offspring were used to examine the expression activities of the OSRAM2 promoter in rice roots during the early and late stages of AM symbiosis.

GUS staining was performed as previously described (Jefferson et al. 1987). After immergence in a GUS staining solution (100 mM sodium phosphate buffer [pH 7.0], $10 \mathrm{mM} \mathrm{Na}_{2}$ EDTA, $1 \mathrm{mM}$ potassium ferricyanide, $1 \mathrm{mM}$ potassium ferrocyanide, $0.5 \%$ [wt/vol] Triton X-100, 20\% [wt/vol] methanol, and 5-bromo-4-chloro-3-indoxyl- $\beta$-D-glucuronide cyclohexylammonium salt at $0.2 \mathrm{mg} / \mathrm{ml}$ ), rice plants were vacuum filtrated three times for $5 \mathrm{~min}$ each, incubated overnight at $37^{\circ} \mathrm{C}$, and placed in $50 \%$ ethanol to terminate the reaction. Subsequently, rice roots were fixed by $5 \%$ formaldehyde, $5 \%$ ethanoic acid, and $50 \%$ ethanol; dehydrated with ethanol; and infiltrated and embedded by Paraplast (Sigma-Aldrich, St. Louis, MO, U.S.A.). For the observations, roots were cut into $10-\mu \mathrm{m}$-thick sections using a Leica RM2235 microtome (Leica, Wetzlar, Germany).

\section{ACKNOWLEDGMENTS}

We thank S. Yang (Nanjing University) for providing the pRGEB31 vector and W. Lan (Nanjing University) for the PBI101.1 vector.

\section{AUTHOR-RECOMMENDED INTERNET RESOURCES}

CRISPRdirect: http://crispr.dbcls.jp

CRISPR-PLANT: https://www.genome.arizona.edu/crispr

Phytozome: https://phytozome.jgi.doe.gov

\section{LITERATURE CITED}

Akiyama, K., Matsuzaki, K., and Hayashi, H. 2005. Plant sesquiterpenes induce hyphal branching in arbuscular mycorrhizal fungi. Nature 435 824-827.

An, J., Zeng, T., Ji, C., de Graaf, S., Zheng, Z., Xiao, T. T., Deng, X., Xiao, S., Bisseling, T., Limpens, E., and Pan, Z. 2019. A Medicago truncatula SWEET transporter implicated in arbuscule maintenance during arbuscular mycorrhizal symbiosis. New Phytol. 224:396-408.

Bago, B., Zipfel, W., Williams, R. M., Jun, J., Arreola, R., Lammers, P. J., Pfeffer, P. E., and Shachar-Hill, Y. 2002. Translocation and utilization of fungal storage lipid in the arbuscular mycorrhizal symbiosis. Plant Physiol. 128:108-124.

Bécard, G., Douds, D. D., and Pfeffer, P. E. 1992. Extensive in vitro hyphal growth of vesicular-arbuscular mycorrhizal fungi in the presence of $\mathrm{CO}_{2}$ and flavonols. Appl. Environ. Microbiol. 58:821-825.

Beisson, F., Li, Y., Bonaventure, G., Pollard, M., and Ohlrogge, J. B. 2007. The acyltransferase GPAT5 is required for the synthesis of suberin in seed coat and root of Arabidopsis. Plant Cell 19:351-368.

Beisson, F., Li-Beisson, Y., and Pollard, M. 2012. Solving the puzzles of cutin and suberin polymer biosynthesis. Curr. Opin. Plant Biol. 15: 329-337. 
Bird, D., Beisson, F., Brigham, A., Shin, J., Greer, S., Jetter, R., Kunst, L., Wu, X., Yephremov, A., and Samuels, L. 2007. Characterization of Arabidopsis ABCG11/WBC11, an ATP binding cassette (ABC) transporter that is required for cuticular lipid secretion. Plant J. 52:485-498.

Blilou, I., Ocampo, J. A., and García-Garrido, J. M. 2000. Induction of Ltp (lipid transfer protein) and Pal (phenylalanine ammonia-lyase) gene expression in rice roots colonized by the arbuscular mycorrhizal fungus Glomus mosseae. J. Exp. Bot. 51:1969-1977.

Bonfante, P., and Genre, A. 2010. Mechanisms underlying beneficial plant-fungus interactions in mycorrhizal symbiosis. Nat. Commun. 1:48.

Brands, M., Wewer, V., Keymer, A., Gutjahr, C., and Dörmann, P. 2018. The Lotus japonicus acyl-acyl carrier protein thioesterase FatM is required for mycorrhiza formation and lipid accumulation of Rhizophagus irregularis. Plant J. 95:219-232.

Bravo, A., Brands, M., Wewer, V., Dörmann, P., and Harrison, M. J. 2017. Arbuscular mycorrhiza-specific enzymes FatM and RAM2 finetune lipid biosynthesis to promote development of arbuscular mycorrhiza. New Phytol. 214:1631-1645.

Bravo, A., York, T., Pumplin, N., Mueller, L. A., and Harrison, M. J. 2016. Genes conserved for arbuscular mycorrhizal symbiosis identified through phylogenomics. Nat. Plants 2:15208.

Chabaud, M., Venard, C., Defaux-Petras, A., Bécard, G., and Barker, D. G. 2002. Targeted inoculation of Medicago truncatula in vitro root cultures reveals MtENOD11 expression during early stages of infection by arbuscular mycorrhizal fungi. New Phytol. 156:265-273.

Chen, C., Ané, J. M., and Zhu, H. 2008. OsIPD3, an ortholog of the Medicago truncatula DMI3 interacting protein IPD3, is required for mycorrhizal symbiosis in rice. New Phytol. 180:311-315.

Douds, D. D., Jr., Nagahashi, G., and Abney, G. D. 1996. The differential effects of cell wall-associated phenolics, cell walls, and cytosolic phenolics of host and non-host roots on the growth of two species of AM fungi. New Phytol. 133:289-294

Fiorilli, V., Vallino, M., Biselli, C., Faccio, A., Bagnaresi, P., and Bonfante, P. 2015. Host and non-host roots in rice: Cellular and molecular approaches reveal differential responses to arbuscular mycorrhizal fungi. Front. Plant Sci. 6:636.

Gaude, N., Schulze, W. X., Franken, P., and Krajinski, F. 2012. Cell type-specific protein and transcription profiles implicate periarbuscular membrane synthesis as an important carbon sink in the mycorrhizal symbiosis. Plant Signal. Behav. 7:461-464.

Genre, A., Chabaud, M., Balzergue, C., Puech-Pagès, V., Novero, M., Rey, T., Fournier, J., Rochange, S., Bécard, G., Bonfante, P., and Barker, D. G. 2013. Short-chain chitin oligomers from arbuscular mycorrhizal fungi trigger nuclear $\mathrm{Ca}^{2+}$ spiking in Medicago truncatula roots and their production is enhanced by strigolactone. New Phytol. 198:190-202

Genre, A., Chabaud, M., Faccio, A., Barker, D. G., and Bonfante, P. 2008. Prepenetration apparatus assembly precedes and predicts the colonization patterns of arbuscular mycorrhizal fungi within the root cortex of both Medicago truncatula and Daucus carota. Plant Cell 20: 1407-1420.

Genre, A., Chabaud, M., Timmers, T., Bonfante, P., and Barker, D. G. 2005. Arbuscular mycorrhizal fungi elicit a novel intracellular apparatus in Medicago truncatula root epidermal cells before infection. Plant Cell 17:3489-3499.

Genre, A., Ivanov, S., Fendrych, M., Faccio, A., Zársky, V., Bisseling, T., and Bonfante, P. 2012. Multiple exocytotic markers accumulate at the sites of perifungal membrane biogenesis in arbuscular mycorrhizas. Plant Cell Physiol. 53:244-255.

Gobbato, E., Wang, E., Higgins, G., Bano, S. A., Henry, C., Schultze, M., and Oldroyd, G. E. D. 2013. RAM1 and RAM2 function and expression during arbuscular mycorrhizal symbiosis and Aphanomyces euteiches colonization. Plant Signal. Behav. 8:e26049.

Gutjahr, C., Banba, M., Croset, V., An, K., Miyao, A., An, G., Hirochika, H., Imaizumi-Anraku, H., and Paszkowski, U. 2008. Arbuscular mycorrhiza-specific signaling in rice transcends the common symbiosis signaling pathway. Plant Cell 20:2989-3005.

Helber, N., Wippel, K., Sauer, N., Schaarschmidt, S., Hause, B., and Requena, N. 2011. A versatile monosaccharide transporter that operates in the arbuscular mycorrhizal fungus Glomus sp. is crucial for the symbiotic relationship with plants. Plant Cell 23:3812-3823.

Hwang, J. U., Song, W. Y., Hong, D., Ko, D., Yamaoka, Y., Jang, S., Yim, S., Lee, E., Khare, D., Kim, K., Palmgren, M., Yoon, H. S., Martinoia, E., and Lee, Y. 2016. Plant ABC transporters enable many unique aspects of a terrestrial plant's lifestyle. Mol. Plant 9:338-355.

Jefferson, R. A., Kavanagh, T. A., and Bevan, M. W. 1987. GUS fusions: Beta-glucuronidase as a sensitive and versatile gene fusion marker in higher plants. EMBO J. 6:3901-3907.
Jiang, Y., Wang, W., Xie, Q., Liu, N., Liu, L., Wang, D., Zhang, X., Yang, C., Chen, X., Tang, D., and Wang, E. 2017. Plants transfer lipids to sustain colonization by mutualistic mycorrhizal and parasitic fungi. Science 356:1172-1175.

Keymer, A., Pimprikar, P., Wewer, V., Huber, C., Brands, M., Bucerius, S. L., Delaux, P. M., Klingl, V., Röpenack-Lahaye, E. V., Wang, T. L., Eisenreich, W., Dörmann, P., Parniske, M., and Gutjahr, C. 2017. Lipid transfer from plants to arbuscular mycorrhiza fungi. eLife 6:e29107.

Kosuta, S., Chabaud, M., Lougnon, G., Gough, C., Dénarié, J., Barker, D. G., and Bécard, G. 2003. A diffusible factor from arbuscular mycorrhizal fungi induces symbiosis-specific MtENOD11 expression in roots of Medicago truncatula. Plant Physiol. 131:952-962.

Kumar, S., Stecher, G., and Tamura, K. 2016. MEGA7: Molecular evolutionary genetics analysis version 7.0 for bigger datasets. Mol. Biol. Evol. 33:1870-1874.

Li, X. C., Zhu, J., Yang, J., Zhang, G. R., Xing, W. F., Zhang, S., and Yang, Z. N. 2012. Glycerol-3-phosphate acyltransferase 6 (GPAT6) is important for tapetum development in Arabidopsis and plays multiple roles in plant fertility. Mol. Plant 5:131-142.

Li, Y., Beisson, F., Koo, A. J., Molina, I., Pollard, M., and Ohlrogge, J. 2007. Identification of acyltransferases required for cutin biosynthesis and production of cutin with suberin-like monomers. Proc. Natl. Acad. Sci. U.S.A. 104:18339-18344.

Li-Beisson, Y., Pollard, M., Sauveplane, V., Pinot, F., Ohlrogge, J., and Beisson, F. 2009. Nanoridges that characterize the surface morphology of flowers require the synthesis of cutin polyester. Proc. Natl. Acad. Sci. U.S.A. 106:22008-22013.

Livak, K. J., and Schmittgen, T. D. 2001. Analysis of relative gene expression data using real-time quantitative PCR and the $2^{-\Delta \Delta C T}$ method. Methods 25:402-408.

Luginbuehl, L. H., Menard, G. N., Kurup, S., Van Erp, H., Radhakrishnan, G. V., Breakspear, A., Oldroyd, G. E. D., and Eastmond, P. J. 2017. Fatty acids in arbuscular mycorrhizal fungi are synthesized by the host plant. Science 356:1175-1178.

MacLean, A. M., Bravo, A., and Harrison, M. J. 2017. Plant signaling and metabolic pathways enabling arbuscular mycorrhizal symbiosis. Plant Cell 29:2319-2335.

Maillet, F., Poinsot, V., André, O., Puech-Pagès, V., Haouy, A., Gueunier, M., Cromer, L., Giraudet, D., Formey, D., Niebel, A., Martinez, E. A., Driguez, H., Bécard, G., and Dénarié, J. 2011. Fungal lipochitooligosaccharide symbiotic signals in arbuscular mycorrhiza. Nature 469:58-63.

McGonigle, T. P., Miller, M. H., Evans, D. G., Fairchild, G. L., and Swan, J. A. 1990. A new method which gives an objective measure of colonization of roots by vesicular-arbuscular mycorrhizal fungi. New Phytol. 115:495-501.

Murray, J. D., Cousins, D. R., Jackson, K. J., and Liu, C. 2013. Signaling at the root surface: The role of cutin monomers in mycorrhization. Mol. Plant 6:1381-1383.

Murray, M. G., and Thompson, W. F. 1980. Rapid isolation of high molecular weight plant DNA. Nucleic Acids Res. 8:4321-4326.

Nagahashi, G., and Douds, D. D., Jr. 2011. The effects of hydroxy fatty acids on the hyphal branching of germinated spores of AM fungi. Fungal Biol. 115:351-358.

Naito, Y., Hino, K., Bono, H., and Ui-Tei, K. 2015. CRISPRdirect: Software for designing CRISPR/Cas guide RNA with reduced off-target sites. Bioinformatics 31:1120-1123.

Pfeffer, P. E., Douds, D. D., Jr., Bécard, G., and Shachar-Hill, Y. 1999. Carbon uptake and the metabolism and transport of lipids in an arbuscular mycorrhiza. Plant Physiol. 120:587-598.

Pighin, J. A., Zheng, H., Balakshin, L. J., Goodman, I. P., Western, T. L., Jetter, R., Kunst, L., and Samuels, A. L. 2004. Plant cuticular lipid export requires an ABC transporter. Science 306:702-704.

Remy, W., Taylor, T. N., Hass, H., and Kerp, H. 1994. Four hundredmillion-year-old vesicular arbuscular mycorrhizae. Proc. Natl. Acad. Sci. U.S.A. 91:11841-11843.

Rich, M. K., Vigneron, N., Libourel, C., Keller, J., Xue, L., Hajheidari, M., Radhakrishnan, G. V., Le Ru, A., Diop, S. I., Potente, G., Conti, E., Duijsings, D., Batut, A., Le Faouder, P., Kodama, K., Kyozuka, J., Sallet, E., Bécard, G., Rodriguez-Franco, M., Ott, T., Bertrand-Michel, J., Oldroyd, G. E. D., Szövényi, P., Bucher, M., and Delaux, P. M. 2021. Lipid exchanges drove the evolution of mutualism during plant terrestrialization. Science 372:864-868.

Roth, R., Chiapello, M., Montero, H., Gehrig, P., Grossmann, J., O'Holleran, K., Hartken, D., Walters, F., Yang, S. Y., Hillmer, S., Schumacher, K., Bowden, S., Craze, M., Wallington, E. J., Miyao, A., Sawers, R., Martinoia, E., and Paszkowski, U. 2018. A rice serine/ threonine receptor-like kinase regulates arbuscular mycorrhizal symbiosis at the peri-arbuscular membrane. Nat. Commun. 9:4677. 
Schaffer, G. F., and Peterson, R. L. 1993. Modifications to clearing methods used in combination with vital staining of roots colonized with vesicular-arbuscular mycorrhizal fungi. Mycorrhiza 4:29-35.

Shachar-Hill, Y., Pfeffer, P. E., Douds, D., Osman, S. F., Doner, L. W., and Ratcliffe, R. G. 1995. Partitioning of intermediary carbon metabolism in vesicular-arbuscular mycorrhizal leek. Plant Physiol. 108:7-15.

Smith, S. E., and Read, D. J. 2008. Mycorrhizal Symbiosis. 3rd ed. Academic Press, London, U.K.

Smith, S. E., and Smith, F. A. 2011. Roles of arbuscular mycorrhizas in plant nutrition and growth: New paradigms from cellular to ecosystem scales. Annu. Rev. Plant Biol. 62:227-250.

Spatafora, J. W., Chang, Y., Benny, G. L., Lazarus, K., Smith, M. E., Berbee, M. L., Bonito, G., Corradi, N., Grigoriev, I., Gryganskyi, A., James, T. Y., O’Donnell, K., Roberson, R. W., Taylor, T. N., Uehling, J., Vilgalys, R., White, M. M., and Stajich, J. E. 2016. A phylum-level phylogenetic classification of zygomycete fungi based on genomescale data. Mycologia 108:1028-1046.

Strullu-Derrien, C., Kenrick, P., Pressel, S., Duckett, J. G., Rioult, J. P., and Strullu, D. G. 2014. Fungal associations in Horneophyton ligneri from the Rhynie Chert (c. 407 million year old) closely resemble those in extant lower land plants: Novel insights into ancestral plant-fungus symbioses. New Phytol. 203:964-979.

Sun, J., Miller, J. B., Granqvist, E., Wiley-Kalil, A., Gobbato, E., Maillet, F., Cottaz, S., Samain, E., Venkateshwaran, M., Fort, S., Morris, R. J., Ané, J. M., Dénarié, J., and Oldroyd, G. E. D. 2015. Activation of symbiosis signaling by arbuscular mycorrhizal fungi in legumes and rice. Plant Cell 27:823-838.

Tang, N., San Clemente, H., Roy, S., Bécard, G., Zhao, B., and Roux, C. 2016. A survey of the gene repertoire of Gigaspora rosea unravels conserved features among Glomeromycota for obligate biotrophy. Front. Microbiol. 7:233.

Taylor, T. N., Remy, W., Hass, H., and Kerp, H. 1995. Fossil arbuscular mycorrhizae from the Early Devonian. Mycologia 87:560-573.

Trépanier, M., Bécard, G., Moutoglis, P., Willemot, C., Gagné, S., Avis, T. J., and Rioux, J. A. 2005. Dependence of arbuscular-mycorrhizal fungi on their plant host for palmitic acid synthesis. Appl. Environ. Microbiol. 71:5341-5347.

Vierheilig, H., Coughlan, A. P., Wyss, U., and Piche, Y. 1998. Ink and vinegar, a simple staining technique for arbuscular-mycorrhizal fungi. Appl. Environ. Microbiol. 64:5004-5007.
Wang, B., and Qiu, Y. L. 2006. Phylogenetic distribution and evolution of mycorrhizas in land plants. Mycorrhiza 16:299-363.

Wang, E., Schornack, S., Marsh, J. F., Gobbato, E., Schwessinger, B., Eastmond, P., Schultze, M., Kamoun, S., and Oldroyd, G. E. D. 2012. A common signaling process that promotes mycorrhizal and oomycete colonization of plants. Curr. Biol. 22:2242-2246.

Wang, S., Chen, A., Xie, K., Yang, X., Luo, Z., Chen, J., Zeng, D., Ren, Y., Yang, C., Wang, L., Feng, H., López-Arredondo, D. L., Herrera-Estrella, L. R., and Xu, G. 2020. Functional analysis of the OsNPF4.5 nitrate transporter reveals a conserved mycorrhizal pathway of nitrogen acquisition in plants. Proc. Natl. Acad. Sci. U.S.A. 117: 16649-16659.

Wang, W., Shi, J., Xie, Q., Jiang, Y., Yu, N., and Wang, E. 2017. Nutrient exchange and regulation in arbuscular mycorrhizal symbiosis. Mol. Plant 10:1147-1158.

Waschburger, E., Kulcheski, F. R., Veto, N. M., Margis, R., MargisPinheiro, M., and Turchetto-Zolet, A. C. 2018. Genome-wide analysis of the glycerol-3-phosphate acyltransferase (GPAT) gene family reveals the evolution and diversification of plant GPATs. Genet. Mol. Biol. 41:355-370.

Wewer, V., Brands, M., and Dörmann, P. 2014. Fatty acid synthesis and lipid metabolism in the obligate biotrophic fungus Rhizophagus irregularis during mycorrhization of Lotus japonicus. Plant J. 79:3 98-412.

Wipf, D., Krajinski, F., van Tuinen, D., Recorbet, G., and Courty, P. E. 2019. Trading on the arbuscular mycorrhiza market: From arbuscules to common mycorrhizal networks. New Phytol. 223:1127-1142.

Xie, K., Zhang, J., and Yang, Y. 2014. Genome-wide prediction of highly specific guide RNA spacers for CRISPR-Cas9-mediated genome editing in model plants and major crops. Mol. Plant 7:923-926.

Yang, W., Pollard, M., Li-Beisson, Y., Beisson, F., Feig, M., and Ohlrogge, J. 2010. A distinct type of glycerol-3-phosphate acyltransferase with $s n-2$ preference and phosphatase activity producing 2-monoacylglycerol. Proc. Natl. Acad. Sci. U.S.A. 107:12040-12045.

Yang, W., Simpson, J. P., Li-Beisson, Y., Beisson, F., Pollard, M., and Ohlrogge, J. B. 2012. A land-plant-specific glycerol-3-phosphate acyltransferase family in Arabidopsis: Substrate specificity, sn-2 preference, and evolution. Plant Physiol. 160:638-652.

Zhang, Q., Blaylock, L. A., and Harrison, M. J. 2010. Two Medicago truncatula half-ABC transporters are essential for arbuscule development in arbuscular mycorrhizal symbiosis. Plant Cell 22:1483-1497. 